\title{
DEVELOPING A HOLISTIC WELLNESS MODEL
}

\author{
DA ELS \\ dels@momentum.co.za \\ RP DE LA REY \\ rdelarey@icon.co.za \\ Dept of Human Resource Management \\ University of Johannesburg
}

\begin{abstract}
The objective of the present study was the development of a holistic theoretical wellness model that served as frame of reference for the construction of a valid and reliable inventory that was considered suitable for the assessment of wellness of employees of a South African life insurance organisation. The 5 Factor Wellness Inventory was developed from existing proven wellness inventories. A non-random sample of 673 employees of the organisation concerned participated in a cross-sectional survey by completing the Inventory and a biographical questionnaire. Goodness of fit between the holistic wellness model and a data set derived from the application of the 5 Factor Wellness Inventory was determined empirically. The structural equation modelling statistics produced acceptable goodnessof-fit indices albeit with some scope for improvement. The Root Mean Square Error of Approximation indices supported acceptance of the holistic work-wellness model. The validity of the Inventory was also estimated.
\end{abstract}

Key words

Holistic, theoretical, wellness model, assessment of wellness

In this article, the development of a theoretical holistic model that explained wellness was initially described. The contents of this wellness model provided a conceptual understanding of all the relevant factors that explain holistic wellness. The holistic wellness model contributed to theory building in the fields of organisational and positive psychology (psychofortology).

The Indivisible Self: An Evidence-Based Model of Wellness that consists of 17 wellness and 4 contextual factors is an existing inventory that was successfully used abroad as a clinical wellness model in an organisational context (Myers and Sweeney, 2005). This wellness model served as base for the empirical assessment of the tenability of the 5 Factor Wellness Inventory. A principalaxes factor analysis of a data set obtained by means of the new wellness inventory, for the first time ever in a South African study, confirmed the factor structure of previous wellness research done abroad. Statistics of the wellness model, produced by structural equation modelling, confirmed a 19 -factor model with reasonably goodness-of-fit indices. The empirical research data confirmed the appropriateness of The Indivisible Self: An Evidence-Based Model of Wellness for the insurance organisation. This wellness model could therefore be used as an independent model to explain wellness in terms of existing theory as well as from the results of the current empirical study.

Research applications in the field of positive organisational behaviour as part of the paradigm of fortology are rapidly increasing. Both psychofortology and positive psychology support the development of strengths inherent in human behaviour. Research into health and wellness in working contexts contribute to the building of theory in the field of industrial psychology.

Current research into the phenomenon of wellness is fragmented. Relevant studies, furthermore, usually focus on analyses of patterns of relationship between the constituent components of well-being. Studies of this nature inevitably require co-relational research designs. In addition, generation of theory regarding the phenomenon of wellness, as a scientific objective, especially in organisations, is limited and generally lacks a holistic and systemic perspective.

Several Wellness models were developed in the field of clinical psychology. These models seldom were appropriate for working environments. The Wheel of Wellness (Sweeney \& Witmer, 1991; Witmer \& Sweeney, 1992), The Indivisible Self: An EvidenceBased Model of Wellness (Myers \& Sweeney, 2005) and the Perceived Wellness Model (Adams, Bezner and Steinhardt, 1997) are some of the more recent wellness models. The Wheel of Wellness model, as was the case with the other models referred to, has evolved from existing theories that described and analysed components of wellness (Myers \& Sweeney, 2005). Counselling psychology has also produced a number of Wellness models. Wellness models and the many theories that support them, that were generated by the two aforementioned disciplines, however, need to be adapted and incorporated into systemic employee-wellness models if they are to make meaningful contributions to the field of industrial psychology.

\section{Scientific objective of the study}

The scientific objective of the current study was to construct and psychometrically assess the validity of a holistic wellness model that might serve as frame of reference for a major life insurance organisation in South Africa that wanted to implement a series of health and wellness care interventions on behalf of its employees. Innovative research that focuses on a holistic, integrated and systemic understanding of employee wellness is certainly needed if human scientists are to assist organisations to manage health and wellness care of employees effectively.

A holistic employee-wellness model that could contribute to a clearer understanding of the concept work wellness would require integration of a wide range of components of the construct wellness. A systemic model of work wellness that would be widely accepted in the scientific community and working environment, has to be based on an understanding of preceding, independent, moderating and antecedent variables that relate and contribute to the phenomenon of work wellness. Wellness as a dependent variable is conceptualised within the life domains of the: (i) family and social interaction; (ii) work; (iii) spirituality; (iv) emotionality; (v) intellectuality; and (vi) physicality.

Several shortcomings in existing scientific knowledge of wellness in general and work wellness in particular, were briefly mentioned in the introductory remarks in this paper. Besides addressing and eliminating many of these shortcomings, the envisaged work-wellness model also would clarify the applicability of the illness-health-wellness continuum to working environments. The intended wellness model ought to lead to a more accurate assessment of work-wellness levels among employees in organisations. Although the illness side of the continuum was not completely ignored, the existing study mainly focused on the positive elements of the illness-healthwellness continuum. 


|

Figure 1: Illness-health-wellness continuum

\section{Problem statement}

The fact that Wellness is not researched in a positive, holistic, systemic and integrated manner is a cause for concern (Wissing \& Van Eeden, 1997, Wissing, 2000). Researchers in the health and social sciences traditionally used a pathogenic paradigm as point of departure for their investigations and interventions, which implied an orientation towards abnormality, sickness, disease and dysfunction as the direct opposite of wellness (Strümpfer, 1995, 2002). Knowledge thus generated was used to develop ways for treating and preventing each of these undesired states of health. Businesses, institutions and professions, ranging from everyday medical practice to pharmaceutical companies, from the insurance industry to mass media, all turned handsome profits by assisting clients to cope with physical, emotional and behavioural threats as well as by providing the required treatments (Saleebey, 1997). This onesided approach verifies the fact that attention should also be given to wellness research - an approach implied by the opposite side of the illness-health-wellness continuum (Antonovsky, 1987; Seligman \& Csikszentmihalyi, 2000; Strümpfer, 1995; Wissing, 2000). This second approach would thus focus on developing the positive aspects and strengths of human behaviour.

Recently there has been a growing trend among organisations to realise the importance of the so-called human factor (Snyder \& Lopez, 2002). Various disciplines highlight the importance of a "good life" and attend to the total well-being or wellness of people. Multidisciplinary research merges different theoretical perspectives into a more realistic wellness paradigm. Interdisciplinary teams are further better equipped to achieve holistic integration and a better understanding of wellness issues. Members of study disciplines other than psychology, all focus on wellness from their own school of thought and could contribute meaningfully to joint theory building. Dietary, nutritional, health and fitness management are examples hereof but they all tend to avoid a holistic interdisciplinary approach (Adams et al., 1997). Research into and promotion of holistic health and wellness requires an integrated and multidisciplinary approach, even in the case of existing inputs by research psychologists.

Psychology as a profession acknowledges the importance of a holistic understanding of the strengths, coping patterns, adaptive abilities and growth potential of individuals (Antonovsky, 1987; Strümpfer, 1995; Seligman \& Csikszentmihalyi, 2000). It is crucial for psychologists to assist people to achieve higher levels of psychological well-being and wellness (Dunn, 1961, 1977; Wissing \& Van Eeden, 1997). This requires acceptance of the origins of health and psychological strengths as a point of departure. Behavioural activities and personality characteristics that promote wellness and prevent sickness require sound scientific research.

Research should focus on the nature, dimensions and dynamics of wellness at individual, group, organisational and general population levels. It is important to understand how these manifest themselves in various phases of the human life cycle (childhood, adolescence, adulthood, old-age) in different contexts (cultural, interpersonal, work or technological surroundings) and by taking into account internal as well as external risks and protective factors, demographics and other moderating or mediating variables (Dunn, 1961). Socially responsible and ethically respectable programmes based on scientifically validated knowledge (theories and models) must be developed, and the effectiveness and efficacy thereof analysed and evaluated.
Complex philosophical, theoretical and empirical analyses are essential to research of wellness. Both extensive quantitative studies using sophisticated research designs and statistical procedures, as well as rich qualitative investigations exploring new fields of psychological strengths, are needed (Strümpfer, 2002). Many constructs related to the hypothesised main constituent components and clusters of wellness also need clarification (Wissing, 2000) in order to determine to what degree they share common empirical denotation even though their basic conceptualisations might differ. Some of these constructs are well operationalised but others still need more empirical clarification and verification.

Wellness is understood as a total person's approach towards improving the quality of his or her life, health and psychological strengths in proactive and positive ways - both as member of a community and as an employee (Witmer \& Sweeney, 1992). It is acknowledged that wellness is characterised by optimal physical health as well as psychological and social well-being and not by the mere absence of illness. Researching wellness requires an understanding that wellness forms part of a holistic integrated system and that it is not only a subpart of a system (Strümpfer, 2002). A better understanding of wellness, its theoretical and conceptual base and its application in organisations is therefore required. The study under consideration attempted to contribute to this understanding of wellness in working environments, especially from a systemic and holistic perspective.

Widespread attempts had been made to stimulate research into the origins of strengths in all areas of human well-being (Antonovsky, 1987, Strümpfer, 1995 and Seligman \& Csikszentimihalyi, 2000). Maslow (1970) provided direction with his research on growth, self-actualisation and the pursuit of psychological health that should be acknowledged as the beginning of a universal human trend. In the fifties wellness was frequently referred to as wholeness (Adler, 1954) while some theorists mentioned the human psyche's need for integration towards wholeness and health (Jung, 1958, 1960).

Organisations, like individuals, have to take into account a continuum that depicts a state of healthy or normal performance in the middle, with illness and wellness forming the opposing ends of the same continuum (Cameron, Dutton \& Quinn, 2003). Conditions of negative or deviating performance that occur on the left of the continuum and states of positively deviating performance that appear on the right (representing wellness), illustrate different options to consider in approaching organisational development (Cameron, 2003). Negative (illness-health) and positive (health-wellness) deviance refer to aberrations of harmfulness or healthy functioning, at one end of the continuum and virtuous (flourishing) organisations and individuals at the other end (Keyes \& Haidt, 2003).

South African organisations mainly apply a negative (illnesshealth) approach to human resource management by focusing only on the promotion of health, creation of wealth and peak performance as the key indicators of business success (Cameron, Dutton \& Quinn, 2003). They operate in a "negative" domain and rely on a medical-remedial paradigm. These organisations are typified by greed, selfishness, manipulation, secrecy and single-minded focus on winning (Cameron, 2003). It is further reported that the behaviour of individuals working in these organisations are characterised by distrust, anxiety, self-absorption, fear, burnout and feelings of abuse (illness). Industrial conflict, lawsuits, contract breaking and retribution arise while disrespect for others is observable in many interpersonal interactions and relationships within these organisations (Harter, Schmidt \& Keyes, 2003).

Appreciation, collaboration, virtuousness, vitality and meaningfulness typify behaviour at the other extreme of the 
continuum, namely the health-wellness approach. Creating wealth and promoting human wellness are key indicators of success in those organisations that flourish as a result of their employee's wellness (Keyes \& Haidt, 2003). Employee behaviour in these organisations are characterised by trustworthiness, resilience, wisdom, humaneness and high levels of positive energy application. Self-efficacy, optimism, hope, happiness and joy, generosity, perseverance, courage, coping and flow are all indicators of positive organisational behaviour (Seligman, 1998). Interpersonal relationships are based on compassion, loyalty, honesty, respect and forgiveness. Significant attention is thereby given to what makes life, and working life per se, meaningful, optimal and worth living for and these are all emphasised (Cameron, Dutton \& Quinn, 2003).

Clarification of wellness terminology and careful defining of work wellness will explain some of the ambiguity that is often observable among psychologists and developmentalists. In this article, the researcher set out to clarify the phenomenon of wellness with the development of a holistic wellness model specifically of worth to employees.

\section{Impact of the problem}

The illness-health-wellness problems that organisations face influence all life domains of employees (Hettler, 1984). Problems that workers perceive and experience as arising from their physical, emotional, intellectual, social and familial as well as spiritual life domains are currently becoming dilemmas that organisations have to face. All of these quandaries emphasise the fact that wellness is being neglected and that organisations are preoccupied with only illness management.

The economic impact of illness-health-wellness mismanagement can be disastrous. The condition of health of employees and their family members significantly affect absenteeism, productivity in the workplace and employment costs (Gemson \& Eng, 2004). Gemson and Eng reported a loss of $\$ 4.9$ million per year as a result of the prevalence of allergic rhinitis and hay fever. A total cost of $\$ 1141$ per employee per annum in lost productivity occurred in America. Two conditions of illness were accountable for the largest part of this significant loss, namely absenteeism (\$496 per employee per annum) and presenteeism ( $\$ 645$ per employee).

Total paid expenses in terms of medical aid, sick leave pay, severance pay, pension contributions, legal benefits, employee insurance and life cover benefits should all be included in any calculation to understand the total economic impact (Wyatt, 2004).

The Business and Health Care Archive (2004) had concerned itself with the impact of unscheduled absence. The Archive reported that employers spent about $4.4 \%$ of their annual payroll on incidental absence-related benefits such as leave taken for sick days. This survey indicated that employee withdrawal from the workplace led to a large percentage of staff members not being committed to the goals of their employers. Van der Westhuizen (2004) reported that one hundred and fifty million rand per annum was lost by municipal workers in the Cape Metropolis, due to $29 \%$ of the permanent staff taking leave without permission on Fridays and Mondays.

Awareness of the negative impact of illness-health-wellness mismanagement clarifies the importance of and economic benefit derived from the prevention of illness and the promotion of wellness. Too many organisations use a pathogenic approach and accordingly resort to illness recovery models of health: millions are lost because organisations simply do not promote wellness. It is therefore crucial that industrial psychologists take the lead by making available practical and empirically tested wellness models and programmes that promote optimal productivity and that at the same time equip employees with interpersonal flourish and personal thriving. If management is prepared to invest some of its resources in work wellness, the implementation of strategies and organisational development interventions that focus on managed health and wellness care will contribute a great deal to the bottom line of achieving excellence in organisations.

The current research project attempted to address the above and other related issues because of the fact that at this stage management in South Africa generally appeared and still seems to be uninformed about the impact that employee wellness programmes could have on the development of their organisations. This obvious lack of knowledge among managers leads to mismanagement of the health and wellness of employees. This in turn limits growth opportunities for employees, a development that eventually results in undercommitment of staff within organisations. Optimum health and wellness management can lead to optimal productivity and flourishing organisations. The required interventions should be based on recognition of and support for the rights of individuals to determine and manage their own quality of life and the promotion of it in the working environment (Huiskamp, 2004). This early in the new millennium particular organisations should accept responsibility by supporting employed individuals to develop their own wellness, and by doing so, also enabling their respective organisations to also benefit financially and otherwise from this. A proactive approach to develop employees' wellness is generally lacking in South Africa and elsewhere; research studies need to be undertaken to promote its potential benefits actively among organisations. Development of the intended holistic wellness model in the current research project would therefore provide support to studies that focus on the evaluation of managed health and wellness care interventions.

The stated need of the current research to develop a holistic wellness model is attributable to the fact that wellness is an integrated construct that cannot be researched in bits and pieces at any particular time. The development of an integrated wellness model would help managers to understand wellness as a holistic system and would also enable Human Resources consultants to design and implement specific programmes that address illness, health and wellness needs in particular organisations. A quasi-model of holistic wellness would make assessment of interactions that occur between constructs of wellness possible while a true holistic wellness model would integrate the effects of all of these dynamic wellness factors into an integrated experience of wellness. The envisaged model to some extent would involve the research discipline of positive organisational scholarship. Its particular contributions towards managed health and wellness care as well as building of theory are seen as essential.

\section{Health and wellness}

The World Health Organisation had defined optimal health as a state of complete physical, mental, and social well-being and not merely the absence of disease or infirmity. Wissing (2000) added further perspective by stating that the salutogenic/fortigenic paradigm at metatheoretical level implies that it is important to focus on the health, strengths and capabilities of human beings. Many researchers (Adams et al., 1998; Dunn, 1961) have contributed various useful definitions of the term wellness but for the purposes of this research project, the comprehensive definition provided by Myers and Sweeney (2005) was preferred. They defined wellness as a way of life aimed at optimal health and well-being in which an individual integrates body, mind and spirit so as to live more fully within the human and natural context. Ideally, it is an optimal state of health and well-being that each 
individual is capable of achieving in all domains of his or her life (Myers, Sweeney and Witmer, 2001). An important prerequisite for the intended development of a wellness model is the acquisition of optimal physical, emotional and mental states while working.

Acquiring wellness at work could be described as a total systems approach that incorporates development of an optimal self and pursuit of quality of life by applying all constructs that are observable in and relevant to a working environment. A focus on strengths as well as contextual variables that influence human behaviour at work is required. This would ensure that all human and other subsystems are integrated into a holistic and systemic perspective on both the theory of work wellness and on wellness models. Knowledge derived from such holistic wellness theories would enable business leaders to understand a systemic approach to manage wellness of employees better and to equip them to judge the merits of its application.

Managers often attend meticulously to an analysis of organisational culture and climate as indices and measures of staff morale. Organisational leadership that diagnose their companies in this way invariably get valuable snapshots of important indicators that enable them to intervene and transform their organisation's culture towards an ideal state (Keyes \& Haidt, 2003). Such measures are of limited use in any assessment since they do not necessarily help management to understand the health and wellness needs of the human capital employed in their company. The result is that the potential of employees is not utilised to its fullest extent. Any reactive approach would lead to a depletion of individual and organisational resources, and in time to come would result in burnout of both management and staff (Redelinghuys \& Rothmann, 2004). Effective meeting of strategic needs also requires a focus on what is not so clearly visible below the "waterline" of the human capital "iceberg".

The full development of the underlying competence and internal psyche of employees is of great importance in organisational health and wellness care. It also suggests that organisations should rely on a proactive approach to development instead of turning to a reactive pathogenic paradigm that aims to develop human capital according to a model of treatment of illness. The present research project addressed the particular dilemmas that management is facing in order to assist it to understand holistically how both individuals and organisations could move towards wellness (Crose, Nicolas, Gobble \& Frank, 1992).

The paradigm of positive psychology provided a valuable framework for studying wellness in organisations as an emerging field. Controlled venture into to this field of study could lead to the formulation of new theories and to an expansion of existing ones, thus enabling researchers of wellness to broaden their understanding of the functioning of human wellness. Research that could analyse and describe how people develop wellness could lead to a richer and deeper understanding of their experiencing of wholeness and their awareness of their own inner strengths (Adler, 1954, 1973; Antonovsky, 1987, 1993). Whenever research outcomes improve scientist's understanding of wellness in organisational contexts, such contributions at the same time add value to the field of organisational psychology as well.

Overall, existing conceptual foundations, models and theories of wellness, for several reasons, so far have had limited impact on wellness research. Underutilisation of these research tools in research projects, unfortunately, led to a scarcity of research outcomes on wellness for use in further research: their appropriateness and possible applications thus lacked adequate empirical evaluation. Wellness concepts, models and theories seldom in any meaningful way led to the phrasing of vital research questions or to the directing of programme contents, design and development. Despite these shortcomings, several theories and models of wellness, nonetheless, guided the present researcher who was interested in the origins, dynamics and the possibilities of wellness enhancement, by making him sensitive to the complex structures, situations and circumstances that characterise this psychological phenomenon. The researcher used existing theories to test specific hypotheses on wellness while available models were adapted to produce a work-related model of the phenomenon. A study of causal interdependencies between psychological constructs and organisational factors as well as their practical applications, produced a new work-wellness model. This new holistic model of work wellness also required proper validation.

\section{RESEARCH DESIGN}

\section{Research approach}

In general research of excellence requires a careful validation of any new conceptual model (or theory) to ensure that all relevant constructs, components, concepts and principles are fully integrated into it before an attempt is made to put into practice. The aforementioned brief guidelines were followed in the current project. In practice, research ideals are sometimes not met while limitations become apparent as the research process evolves. These and other confounding factors and events in the current project were acknowledged, accepted and duly reported on.

The research project under consideration was broadly conducted in four phases. At first, it was investigative by nature and consisted of an extensive survey of available literature on work wellness. In the second stage, the outcome of this overview of literature was used to assess the complexity, nature and interrelatedness of components of wellness and also to identify measurable variates (a variate is a variable and a set of individual test scores linked to it) that were likely to be considered for inclusion in a preliminary model of employee wellness. Thirdly, this prior model of employee wellness was converted into a brief wellness questionnaire that was researched and validated by means of a cross-sectional survey design (Bethlehem, 1999). Finally, a new holistic wellness model was formulated from the results of an extensive empirical investigation involving advanced statistical methods. The current research project thus contributed towards an expansion of both theoretical and applied behavioural science by initially identifying and mapping variables linked to a holistic wellness model and by finally integrating these into an empirically verified model that could be used in working environments.

The cross-sectional survey design lent itself to the examination of stable, long-term states or conditions and allowed the researcher to make inferences from the sample that could be generalised to different populations. The empirical study identified connections between variates and wellness constructs that were not ascribable to any planned intervention as these were measured and assessed by means of a validated and unbiased work-wellness inventory.

Practical research problems that were addressed in the design included errors of measurement. Respondents for instance did not understand specific questions in the measuring instrument, processing errors occurred, coding mistakes were made during data capturing and the thirdvariable problem (where a high correlation between two variables could have been attributed to a third variable that correlated significantly with them) had to be managed. One of the profound practical problems of the chosen design was the fact that it was almost impossible to establish causation between co-related variates. A pilot study was conducted to identify important sources of error of measurement. The Statistical Consultation Services of the University of 
Johannesburg suggested several controlling techniques to limit processing errors. Techniques such as multiple regression and structural equation modelling are normally used to compensate and account for third-variable problems.

\section{Participants}

The study population of the current research project consisted of employees of a major life insurance company in South Africa. The staff complement of this organisation consisted of 2523 employees. A non-random sampling strategy based on availability, determined the composition of the sample. All participants, drawn from the different business units within the organisation under consideration, volunteered to partake in the present study. None of them had previously participated in wellness studies. Altogether 673 employees $(26.70 \%$ of the total staff count) were included in the actual sample. The sample of participants was judged as being representative of the staff complement of the organisation. Detailed assignment of subjects from the population to the sample approximated the distribution of biographic attributes of the former in terms of race, marital status, gender, qualifications and years of service.

The sample drawn in the study mainly consisted of employees from the company's business area Client Services. Married employees $(n=377)$ formed about $50 \%$ of the sample. Females made up $63 \%$ of the sample. The actual sample predominantly consisted of Whites while lesser numbers of Coloured, African and Indian employees were included. The allotment of Afrikaans, English and African speaking employees was similar to that of the organisation. The sample was also representative in terms of age distribution: most participants were in the twenty-six to thirty $(n=191)$ age group. The age category thirty-six to forty $(n=171)$ formed the second biggest age group. The characteristics of the sample were detailed in Table 1.

TABLE 1

Characteristics of THE SAMPle

\begin{tabular}{|c|c|c|}
\hline \multirow[t]{7}{*}{ Completed years of service } & Less than 1 year & 70 \\
\hline & One to two years & 51 \\
\hline & Two to three years & 133 \\
\hline & Three to five years & 139 \\
\hline & Five to ten years & 156 \\
\hline & Ten years and more & 121 \\
\hline & Missing & 3 \\
\hline \multirow{6}{*}{ Highest academic qualification } & Less than matriculation & 22 \\
\hline & Matric & 402 \\
\hline & Bachelors degree & 161 \\
\hline & Honours degree & 58 \\
\hline & Masters degree & 10 \\
\hline & Missing & 20 \\
\hline \multirow[t]{5}{*}{ Home language } & African & 183 \\
\hline & English & 202 \\
\hline & Afrikaans & 276 \\
\hline & Other & 9 \\
\hline & Missing & 3 \\
\hline \multirow[t]{5}{*}{ Race } & African & 125 \\
\hline & White & 402 \\
\hline & Coloured & 76 \\
\hline & Indian or Asian & 63 \\
\hline & Missing & 7 \\
\hline \multirow[t]{6}{*}{ Marital status } & Single & 219 \\
\hline & Married & 377 \\
\hline & Separated & 6 \\
\hline & Divorced & 57 \\
\hline & Widowed & 10 \\
\hline & Missing & 4 \\
\hline \multirow[t]{3}{*}{ Gender } & Male & 245 \\
\hline & Female & 424 \\
\hline & Missing & 4 \\
\hline
\end{tabular}

The contents of Table 1 in some instances reflected missing values. Some participants had left out biographical information or did not respond to all questions in the measuring instrument. In these cases, incomplete data was termed missing data.

\section{Measuring instrument}

A single questionnaire, the 5 Factor Wellness Inventory (5F-Wel Inventory) was used to measure and assess the different wellness factors. The validity of this measuring device was empirically assessed in terms of its rationale, development, contents, psychometric properties, administration, scoring and reliability. The wellness-measuring device took approximately thirty minutes to complete. Variables such as the age of participants and others could have had an effect on the results of the study. A biographical questionnaire was therefore included to control for possible bias effects from variables such as age, gender, length of service and educational background.

The original 5 Factor Wellness Inventory was specifically designed to assess the characteristics of wellness and to help individuals in making choices toward healthier living (Myers \& Sweeney, 2005). An early version of the instrument, the Wellness Evaluation of Lifestyle (WEL), was published in 1998 (Myers \& Sweeney, 2003, 2005). The WEL was constructed from the results of a number of cross-disciplinary research studies to assess 17 wellness areas identified as correlates of health, quality of life, and longevity that were depicted in a theoretical wheel model. The Wellness Inventory is based on confirmation of a single higher-order wellness factor, five second-order factors as well as 17 third-order factors representing the original hypothesised areas of wellness. The seventeen areas are grouped as follows within the five second-order factors:

- Creative Self - thinking, emotions, control, work, positive humour.

- Coping Self - leisure, stress management, self-worth, realistic beliefs.

- Social Self - friendship, love.

- Essential Self - spirituality, gender identity, cultural identity, self-care.

- Physical Self-nutrition, exercise.

The original wellness model and inventory by construction and nature are ecological as both include local, institutional, global, and chronometrical items as contextual variables. The 5F-Wel Inventory contained 73 items that were scored on scales representative of the higher-order total wellness, the five factors of the self, and the 17 third-order factors. Contextual variables in turn were assessed by 18 items that at present are considered experimental since norms for these are not yet available. American norms for both genders and ethnic minority groups are available and are based on data provided by more than 2093 individuals of varying ages across the full lifespan.

Previous reliability estimates provided alpha coefficients that were uniformly high for the first- and second-order factors: Total Wellness, 0.90; Creative Self, 0.92; Coping Self and Social Self, 0.85; and Essential Self and Physical Self, 0.88. Third-order factor alpha coefficients ranged from 0.70 to 0.87 for all but two of the scales: Self-Care, 0.66 and Realistic Beliefs, 0.68. Use of the scales in numerous dissertation and other studies provided evidence of both convergent and divergent validity when compared with constructs such as ethnic identity, acculturation, body image, self-esteem, and gender role conflict.

Researched literature confirmed that the 5F-Wel was the instrument that best supported the assessment of holistic wellness. This inventory had produced satisfactory reliability and validity coefficients in previous studies. The original 5F-Wel measuring instrument was slightly adjusted to improve its fit to and application in South African circumstances. Items that were obviously developed for race groups in the United States of 
America were changed to refer to race groups in the South African context. Use of the 5F-Wel inventory in the current study was its first use ever with a South African population.

\section{Research procedures}

The scientific objective of the current research project required a dedicated research design that was based on ten methodological considerations that also included several practical steps namely:

- Step 1: The researcher did a survey of literature to extract knowledge that would lead to a clear holistic conceptualisation of wellness and further the identification of constituent components and elements of wellness that influenced the behaviour and functioning of employees.

- Step 2: Retrieved information about the components and elements of wellness guided the choice of items from existing psychometric tests of general wellness. Items that were provisionally judged as suitable for inclusion in a wellness test appropriate for use in a working environment, were identified. Selected items were mostly taken from the original 5 Factor Wellness Inventory and included in a shortened psychometric test called the 5F-Wel Inventory. Availability and administration of the 5F-Wel Inventory guided several aspects of the empirical study, such as the research design as well as the construction, assessment and validation of the final version of the holistic model.

- Step 3: A formal sample was drawn; the research group was introduced to the researcher, informed of the purpose, method, and procedures of the study while participant's consent to data access were obtained.

- Step 4: The 5F-Wel Inventory was taken down individually. Participants responded to all variables included in this measuring device by answering all questions in the inventory in a single test session.

- Step 5: Test-generated raw data, namely the original individual responses of sampled participants to the test items in the 5F-Wel Inventory, was captured in a data set. This data set of $5 \mathrm{~F}-$ Wel Inventory variates was observable and unfactored, since it had not yet been subjected to structural change through statistical manipulation.

- Step 6: The unfactored set of variates was statistically analysed to generate provisional feedback for participants. Participants' personal results were confidential and handled as such.

- Step 7: The unfactored set of variates next was transformed by means of principal-axis factor analysis into a factored data set that included the factor scores of participants. This method extracts latent factor structures that underlie an original set of variates. Latent scores are not directly observable in an unfactored data set. The extracted latent factor structures and weights or loadings, produced factor scores for each participant.

- Step 8: The factor structures produced by the principal-axis factor analysis were also used to construct and describe the new wellness model that was the principal scientific objective of the current study. The validity of the constructs linked to the new wellness model was also verified by means of visual and verbal inspection of the wellness structures. Reliability estimates, such as the consistency of factor scores produced by the 5F-Wel Inventory, provisionally were made by using Cronbach's formula for the calculation coefficient alpha.

- Step 9: The validity of the wellness model was also determined by means of statistical structured equation modelling. This approach to modelling determined the goodness of fit between the observable or unfactored sets of variates and the latent or factored data set. From a statistical perspective, good fit between the two data sets would confirm the validity of the holistic wellness model.

- Step 10: All available research information on wellness was integrated into a single body of scientific knowledge that was handed over to the South African insurance organisation that became involved in the research project. A number of conclusions and recommendations were made while guidelines for future research regarding the implementation of wellness interventions were provided.

\section{Statistical analysis}

Parts of the statistical analysis were done with the SAS programme (SAS Institute, 2000). Three types of statistics were calculated with the SAS programme, namely descriptive statistics, correlation coefficients and Cronbach estimates of reliability. All factor analytic calculations that were needed to examine factor structures were done by means of the SPSS Windows programme (Ferguson \& Takane, 1989). The extraction method used to determine the factor structure was that of principal-axes factoring. The Oblimin approach with Kaiser's normalisation was used for the purpose of rotation. The AMOS programme (Arbuckle, 1999) was used for the structural equation model. The statistical methods were explained in more detail elsewhere.

The scientific study of wellness is a difficult assignment. The construct is multifaceted; studying it involves a multitude of variables and variates as well as requiring use of advanced multivariate statistics. High-level research focuses on examining and understanding of patterns of co-relatedness or interdependence between sets of variates. Several indices of corelation are available to describe and analyse patterns of interrelatedness. Inspection of any large matrix of indices of corelation immediately shows that no simple intuitive interpretation of the pattern of co-relations among a set of variables is possible (Ferguson \& Takane, 1989). Two issues complicate analysis. Firstly, two kinds of co-relationships or covariance occur. Variates might co-relate with several other variates in a data set. Variates of this type appear to measure part of a common construct since they share communality. Their mere presence in a data set suggests duplication of observed variates. A particular variate might not co-relate at all with any other remaining variates. It thus might measure a unique component of a construct that is limited to one variate in the set. Secondly, aggregates of variates tend to form clusters or patterns of co-relationship: some of these patterns are observable while others underlie or are latent in a set of variates and thus are difficult to observe. Factor analysis is a statistical method that assumes that any set of $m$ variates contains both communality and uniqueness. The method employs these two properties to convert the original scores linked to the variates (raw or unfactored data) into factor scores (factored data) and uses these to reduce the variables to create a simplified structure. Reduction implies that the patterns of the original variates and transformed factor scores differ noticeably: the converted set carries the latent structure (Harris, 1975).

Factor analysis requires an unfactored or raw data set consisting of an aggregate of individual test scores linked to a set of $\mathrm{m}$ variates. The statistical method converts the original raw data into either an $\mathrm{m} \times \mathrm{m}$ intercorrelation matrix or variancecovariance matrix. Statistical data that forms the elements of a matrix is obtained by pairing off each variable with every other in the set to calculate their communality or uniqueness. The elements of a matrix thus reflect the patterns of co-relation between all of the available $\mathrm{m}$ variates. The $\mathrm{m} \mathrm{x} \mathrm{m}$ matrix next is transformed into a factor matrix. An index, such as $\mathrm{R}^{2}$ that estimates communality of variates, is selected from the contents of a matrix. One variate at a time is compared with all remaining variates in the set. Their indices of co-relatedness in the matrix are then converted into factor scores by multiplying the element values by the estimated index of communality to produce a set of weights or loadings that describes the latent or underlying structure of the original variates in the derived factor. Summation of the factor loadings produce sets of Eigen values or $\lambda$ values. The calculation procedures are iterative. Once a set of factor loadings for a particular variate is extracted, the procedure reduces the intercorrelation or variancecovariance matrix before a next set of factors for a second 
variate is calculated. The matrix with its factor loadings, form an unrotated matrix. The contents of the unrotated factor matrix are plotted on a graph where after some method of axis rotation transforms it into a new set of factor loadings. The new loadings form a rotated factor matrix that simplifies and improves the interpretation of factor structures. These steps produce a firstorder factor analysis. A next factor analysis of a matrix of factor loadings obtained from a previous factor analysis produces a second-order factor analysis.

In theory, the number of factors extracted by means of factor analysis usually equals the original number of variates in the data set. Reduction or simplified structure is achieved by means of the size of the Eigen values. A researcher can reduce the number of factors in a data set by comparing their $\lambda$ values with some or other criterion, such as that of Kaiser. Kaiser suggests use of $\lambda>1.00$ as cut-off point to isolate the more important factors that explain significant amounts of individual differences from those that are considered trivial because they contribute very little (Ferguson \& Takane, 1989).

Some final comments on the use of factor analysis in the current study were necessary. In this article, only the results of the firstorder factor analysis were reported. All Eigen values related to the factors were omitted purposefully. Any attempt to reduce and simplify underlying factor structures was considered as inconsistent with a holistic approach to the proposed wellness $\lambda$ model. The omission of $\lambda$ values, however, could be problematic. Factors that play a trivial role by design are included in the results. These factors usually are the latter ones that contribute towards a model or a factor structure. Their interpretation could confound the quality of the holistic model of wellness. Different types of factor analyses achieve different outcomes. For the purposes of the current study principal-axes, factor analysis was used to convert the initial matrix. This type of factor analysis was a prerequisite for the intended study as it analyses the relationship between a set of test variates and its derived factors (Overall \& Klett, 1972).

Cronbach's alpha coefficients (also called coefficients $\alpha$ ) as well as interitem correlation coefficients were calculated to assess the internal consistency of the measuring instrument (Clark \& Watson, 1995). A psychometric test measures consistently when all items in an instrument measure a common characteristic; it describes the extent to which a set of test items are consistent with the construct that it is supposed to measure (Huysamen, 1994). Multiple measures with the same test are judged as reliable if they reproduce consistent values. Reliability differs from validity in that it relates not to what is being measured but instead how dependable it is measured. Cronbach's coefficient alpha is a measure of reliability and ranges from 0,00 to 1,00 , with values of 0,60 to 0,65 suggested as lower limit of acceptance. Interitem correlation coefficients were used to determine whether the internal consistencies of the constructs were not so high as to affect the validity of the 5 Factor Wellness Scale. Clark and Watson (1995) regarded interitem correlations between 0,15 and 0,50 as acceptable.

Descriptive statistics that included the arithmetic mean (M), standard deviation (SD), skewness and kurtosis were calculated for both the questionnaire and its underlying factor structures. Means, standard deviations, skewness and kurtosis are techniques used to describe characteristics of the variables in a data set and to compare results. The arithmetic mean is the bestknown measure of central tendency. This specific value is most representative of the original set of scores from which it was calculated. A standard deviation denotes the distribution of individual scores above and below the arithmetic mean; a high standard deviation infers that this distribution of scores are widely scattered around the mean (Steyn, Smit, Du Toit \& Strasheim, 1995). Two components of normality were calculated, namely skewness and kurtosis. An index of skewness points to symmetry or asymmetry in the spread of individual scores around the arithmetic mean of a data set. The kurtosis index describes the peak of the distribution of a tabulated set of individual scores that might be mesokurtic (normal bell-shape), platykurtic (flatter that normal) or leptokurtic (higher-peaked than normal).

A psychological theory of a phenomenon (construct) consists of a number of propositions or statements, called indicators of the construct that links a set of construct-related test variates in a pattern of causal relationship. Structural equation modelling (SEM) is a statistical method that examines the plausibility of complex behavioural theories or models about noteworthy constructs that researchers have formulated for testing and verification. The method uses linear structural equation to test and assess interrelationships between a reproducible set of observable or measurable individual scores on a number or variates and an underlying or latent operational definition of an important construct to which the set of variates presumably relates. Structural equation modelling eventually demonstrates the consistency and tenability of propositions about causal relationship that a model or theory implies. The statistical method calculates structural equations by means of linear analysis that yield constants, regression weights, path coefficients, intercorrelations, errors of measurement and estimates of latent variables to determine the plausibility of a particular model. The complex interrelations between the test variates and the construct scores of the latent variables of a testable model or theory might be stated verbally, presented graphically and visually as a path diagram or be converted into a linear equation formula. SEM analysis requires sound and logical reasoning to formulate statements that clearly express assumed relationships between the set of observed scores of a set of variates and the operationalised latent construct as well as the setting of important parameters.

The AMOS method also calculates several goodness-of-fit statistics that assess the plausibility and acceptability of models. Hypothesised relationships were tested empirically for goodness of fit with the wellness data. According to Jöreskog and Sörbom (1993) the chi-square statistic and several other goodness-of-fit indices, best summarised the degree of correspondence between implied and observed covariance matrices. Byrne (2001) suggested goodness-of-fit indices that require a more pragmatic approach to the evaluation process. The chi-square $\left(\chi^{2}\right)$, the $\chi^{2} /$ degrees of freedom ratio (CMIN/DF), Normed Fit Index (NFI), Tucker-Lewis Index (TLI), Comparative Fit Index (CFI) and the Root Mean Square Error of Approximation (RMSEA) were used in the process. Goodnessof-fit statistics use different statistical and mathematical points of departure and therefore vary in terms of the outcomes they produce. Conclusions based on structural equation modelling often are contradictory and confusing.

The AMOS programme checked for the presence of confounding variables in interrelationships and assessed the contribution of each variable to the work-wellness model by means of a maximum likelihood method. SEM, in general, is a statistical method that requires a confirmatory approach that involves hypothesis testing in the analysis of a structural theory that has a bearing on some phenomenon (Byrne, 2001). All tests of structural equation modelling require sets off parameters that asses a logical order that increases restrictions in every step and by doing so, improves eventual goodness of fit.

\section{RESULTS}

The 5 Factor - Wellness Survey was used to measure the degree to which the test responses of employees in this study complied with the theoretical definition of wellness, as it is defined by The Indivisible Self: An Evidence-Based Model (Myers \& Sweeney, 2005). The reported 5F-Wel descriptive statistics and 
results of the factor analysis were produced by the first empirical application ever of this measuring instrument in South Africa. A search for Cronbach alpha coefficients and interitem correlation coefficients from earlier South African studies produced nothing.

The initial factor analysis was explorative by nature (Clark \& Watson, 1995). This exploratory analysis produced sixteen wellness factors and three contextual factors. The rotated factor structure matrix together with the loadings on each factor was presented in Table 1.

All outcomes that were derived from the first-order factor analysis were reported as the underlying factor structure. According to the results the 91 items of the 5F-Wel loaded on 19 factors (16 wellness factors and 3 contextual factors). Ten factors were valid and reliable with á values in excess of 0.65 . The factor structure produced by the principal-axes factor analysis was interpreted as follows:

- Factor I - Self-worth was formed out of items that suggested acceptance and satisfaction with one-self. This factor was based on items $44,38,36$ and 60 .

- Factor II - Exercise consisted of items 53, 9, 62, 72 and 33 that had to do with regular and frequent physical exercise and activities.

- Factor III - Spirituality had to do with spiritual beliefs, religious activity and spiritual growth. Items that loaded on this factor were numbers 51, 35, 69, 37 and 65.

- Factor IV - Stress Management measured coping with stress and resilience by means of items 2, 18 and 50 .

- Factors V-Love was derived from items 52, 26, 73, 49 and 47. This factor measured stimulation of growth as well as intimate, secure and lasting relationships.

- Factor VI - Gender Identity measured positive attributions related to gender identification as a source of strength and support. Test items 6, 10 and 22 loaded on this factor.

- Factor VII - Realistic Beliefs were construed from items 12, $28,46,56$ and 39 . Being in touch with reality, setting realistic expectations and drawing fair conclusions were measured by these items.

- Factor VIII - Leisure was clustered in the factor analysis around items 41, 1, 61, 34 and 23. Leisure referred to the amount of relaxation, absorption in activity and the quality of leisure that one experienced.

- Factor IX - Humour was reflected in items 4, 54, 42 and 21. This factor measured positive humour and the ability to laugh at oneself.

- Factor X - Intelligence referred to comprehension, problem solving, taking of control, goal attainment, creativity and utilisation of skills. Items that measured the aspects of intelligence were items number $27,48,32,43,20,30,7,57$ and 59 .

- Factor XI - Nutrition was inferred from items 3, 14, 5, 68 and 63. This factor measured the perception of the value of quality food, vitamins, minerals and fibre in a diet.

- Factor XII - Emotion clustered around items referring to regular and appropriate expression of emotion. This factor consisted of items 13, 40 and 71. Item 71: "I am proud of my cultural heritage" could be used as an item suggesting an emotional reaction since pride was mentioned in it. In earlier studies elsewhere, this item loaded on cultural identity.

- Factor XIII - Friendship as a factor clustered around items 11, $25,70,8,55$ and 66 . This factor measured experiencing support from others, sharing of emotion with others (item 66), enjoyment of leisure without guilt (item 55) and consumption of moderate amounts of alcohol (item 8).

- Factor XIV - Self-care referred to the degree to which physical health was protected by preventative actions and was measured by items 64, 15 and 19 .

- Factor XV - Work referred to satisfaction with work, use of abilities and skills as well as autonomy attached to work. It consisted of items 24, 29, 58 and 17.
- Factor XVI - Social Identity loaded on items 45, 31 and 16. This factor referred to gender and cultural identification as a source of strength. Item 57 (gender identity): "I feel a positive identity with others of my gender" did not load significantly on any of the factors.

- Factor XVII - Local Safety was a contextual variable that measured feelings of security in the home, neighbourhood, work and in one's daily life. Items 78, 76, 79, 77, 74 and 75 were designated as contributing to this factor. Item 74 as a general life satisfaction item also loaded on this factor.

- Factor XVIII - Institutional Concern was measured by items $88,82,85,81,83$ and 91 . This factor pointed to attributions towards the government, education, future perspective, other cultures and change as contextual wellness factors. Item 86 (global): "I watch TV less than two hours each day" did not load significantly on any of the factors.

- Factor XIX - Personal Attributions measured by items 90, 80, 89,87 and 84 referred to items related to personal contributions towards happiness and wellness.

TABLE 2

FIRST-ORDER DESCRIPTIVE STATISTICS FOR THE VARIOUS ITEMS OF THE 5 FACTOR WELLNESS SURVEY (5F-WEL)

\begin{tabular}{lccccc}
\hline Factor & Mean & SD & Skewness & Kurtosis & $<$ \\
\hline I & 13,65 & 1,77 & $-0,25$ & $-0,80$ & 0,70 \\
II & 10,45 & 3,11 & 0,02 & $-0,65$ & 0,81 \\
III & 8,01 & 2,86 & 1,22 & 1,96 & 0,86 \\
IV & 9,36 & 1,52 & $-0,38$ & 1,24 & 0,79 \\
V & 7,06 & 2,10 & 0,99 & 0,56 & 0,77 \\
VI & 6,62 & 1,04 & 1,00 & 2,85 & 0,64 \\
VII & 12,10 & 2,32 & $-0,13$ & 0,30 & 0,60 \\
VIII & 9,36 & 2,51 & 0,38 & 0,24 & 0,73 \\
IX & 1,88 & 0,61 & 0,31 & 0,66 & 0,58 \\
X & 27,97 & 2,61 & 0,12 & $-0,12$ & 0,64 \\
XI & 10,41 & 3,08 & 0,21 & $-0,28$ & 0,82 \\
XII & 7,31 & 1,10 & $-0,03$ & 0,47 & 0,47 \\
XIII & 10,72 & 2,57 & 0,28 & $-0,22$ & 0,57 \\
XIV & 8,81 & 1,46 & $-0,37$ & 0,06 & 0,18 \\
XV & 11,77 & 2,03 & $-0,39$ & 0,68 & 0,68 \\
XVI & 5,51 & 1,54 & 0,40 & 0,32 & 0,56 \\
XVII & 11,82 & 2,81 & 0,99 & 0,56 & 0,75 \\
XVIII & 12,55 & 2,54 & 0,12 & $-0,12$ & 0,66 \\
XIX & 9,94 & 2,01 & $-0,03$ & 0,47 & 0,40 \\
\hline & & & & &
\end{tabular}

From the contents of Table 2, it was concluded that most of the factors statistically were reliable and valid in assessing the wellness of employees in a life insurance organisation in South Africa.

The goodness-of-fit indices of the wellness model were reported in Table 3.

TABLE 3

GOODNESS-OF-FIT STATISTICS FOR THE WELNESS MODEL

\begin{tabular}{lcccccc}
\hline Model & $\chi^{2}$ & $\chi^{2} / \mathrm{df}$ & NFI & TLI & CFI & RMSEA \\
\hline Model 1:19 factors & 16828,18 & 4,32 & 0,27 & 0,32 & 0,33 & 0,07 \\
\hline
\end{tabular}

It could be seen from Table 3 that the RMSEA confirmed that the variates in the data set showed good fit to the model. Browne and Cudeck (1993) regard this value as an acceptable and reasonable error of approximation. The $\chi^{2}$-based goodness-of-fit statistic was sensitive to the dimensions of the moment matrix derived from a data set of large proportions: this anomaly produced an unreliable index of model fit. Most $\chi^{2}$ tests and $\chi^{2}$-based indices are N-sensitive, that is sensitive to sample size. The calculated 
$\chi^{2} / \mathrm{df}$ value deviated significantly from the expected value for the theory that was being assessed. The numerical value was therefore rejected as being statistically untenable. In some instances, non-significant chi-square values are desired in order to prove the null hypothesis. The NFI value $(0,27)$ indicated that the model fit could be improved substantially. A NFI of 1.00 would have indicated a perfect fit. The Tucker-Lewis Index (LTI) and Comparative Fit Index (CFI) both pointed to poor fit with values lower than 0,90 (Arbuckle and Wothke, 1999). The most important test, namely RMSEA, indicated a good fit with a value of 0,07. Browne and Cudeck (1993) stated that a value of 0,08 or less for the RMSEA indicated a reasonable error of approximation.

Using the 5F-Wel model as theoretical point of reference, the final wellness model was presented in Figure 2.

The proposed model was an explorative model that was constructed to serve as basis for the development of a holistic work-wellness model. A single value that was produced by an important goodness-of-fit index from the available range of indices, confirmed the validity of the preliminary model. The proposed multivariate wellness model was arrived at from the factor analytic structure produced by a principal-axes factor analysis of the original data set. The goodness of fit between this factor analytic description of a wellness construct and the theoretical approach to it that was represented in the original data set had been tested with the AMOS Basic programme. The results had confirmed and validated good fit for the purposes of future application. The structural model in Figure 2 showed that the insurance organisation might consider all sixteen wellness factors as well as the three contextual factors as components of an independent wellness model for future interventions.

A final word of warning, however, was necessary. As was stated earlier in explaining the statistical analysis, the usual provision of Eigen or $\lambda$ values with the results of the principal-axes factor analysis and use of these to eliminate trivial factors from the model, were done away with for the purposes of the current study to ensure a holistic model of wellness. The negative impact of the two decisions mostly would have affected the latter factors in the wellness construct. From a statistical point of view, this approach would cast some doubt on the tenability of the contextual variates, possibly the social identity variate and perhaps one or two others as well.

\section{CONCLUSIONS}

Conclusions in terms of the results on this section of the study were based on the statistics from the factor analysis and the goodness-of-fit statistics. The factor analysis, with some reservations, pointed to love, leisure, local safety, institutional concern, nutrition, social identity, stress management, spirituality, exercise and self-worth as reliable factors as measured by the 5F-Wel instrument. Goodness-of-fit statistics confirmed good fit (RMSEA) for a wellness model for use in an insurance organisation. However, some indices suggested that modification might be considered to improve the chi-square value, NFI, the Tucker-Lewis Index and the Comparative Fit Index (CFI)

\section{Recommendations}

Based on the literature and empirical findings in this research some recommendations for the organisation and future research were made.

The current study did not consider wellness within the context of selection of staff. Further research was thus required to validate the appropriateness of wellness in this particular organisational context. Measurement of wellness might be used in conjunction with other measures of staff selection to ensure that healthy and well employees are appointed to the organisation.

With regard to the existing staff members of the organisation that had participated in this study, the results indicated that

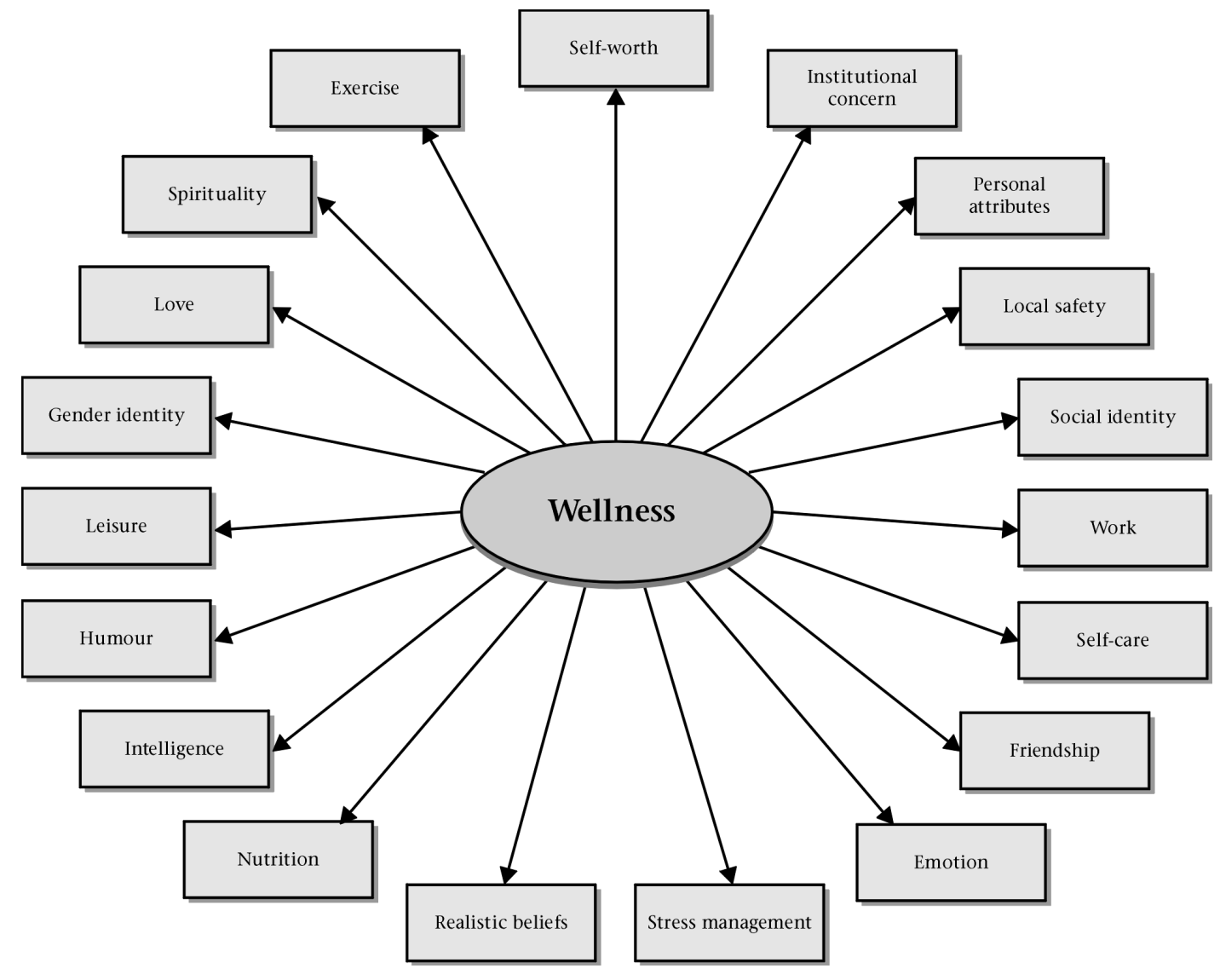

Figure 2: Wellness model 
enhancement of the wellness characteristics of current employees would likely to result in an increase in their productivity, effectiveness, quality of work life and workhome life balance. The researcher, therefore, recommended that employees be made aware of their own wellness dispositions. This might help them to develop their own coping resources that they could use to cope with the demands of corporate working conditions. The organisation in future would also benefit if it designed and implemented interventions that addressed the enhancement and development of employee wellness.

The organisation could further contribute to the development of employee wellness by presenting developmental interventions in a consistent, structured and focused way. By providing employees with the necessary knowledge, skills, material, instruments, support and other resources, the staff members might experience that their job demands are under their personal control. It could well be that employees who were allowed a degree of independence and freedom of choice to selfmanage their own health status, were more likely to act autonomously while at work.

Future research needed to focus on the application of The Indivisible Self: An Evidence-Based Model of Wellness as well as the 5 Factor Wellness Survey and needed to be validated for different age, race and culture groups to provide statistical norms for South African populations and conditions. The moderating influence of organisational factors and other individual dispositions on wellness need investigation to expand on the holistic wellness model presented in this study

In conclusion, greater focus had to be directed at achieving overall wellness and improving the wellness dispositions of employees. Implementation of a strategic health and wellness programme that incorporated all wellness factors that contributed to holistic wellness might reduce sick leave in organisations whilst increasing their profitability at the same time.

\section{Limitations}

The researcher experienced difficulty in finding available research material applicable to the study that focused on holistic organisational wellness. Many fragmented measuring instruments and research studies were found that focused only on some aspects of wellness. Because of this scientific obstacle, the researcher experienced the limitation of applying wellness as opposed to well-being instruments in the study. The wellness instrument that was used, furthermore, was not validated for extensive use in South Africa, as it was the first-ever application of it in this country. The future challenge, therefore, is to experiment with it in conjunction with the American-based 5 Factor Wellness. Holistic wellness research in general was also lacking in South Africa. This resulted in a limitation of having to base local research needs on previous studies of holistic workwellness done abroad.

Reliance on the sole use of self-report data was seen as another limitation, since it was only quantitative by nature. This might have affected or artificially inflated relationships among wellness constructs, individual states and organisational factors. A distinct possibility existed that more objective and explorative indicators of quality of work wellness might yield a different set of outcomes; a combination of self-report measures and qualitative indicators of wellness might have provided richer results.

\section{REFERENCES}

Adams, T.B., Bezner, J.R. \& Steinhardt, M. (1997). The conceptualisation and measurement of perceived wellness: integrating balance across and within dimensions. American Journal of Health Promotion, 12 (3), 380-388.
Adams, T. B., Bezner, J.R. \& Whistler, L.S. (1998). The relationship between physical activity and indicators of perceived wellness. American Journal of Health Studies, 15 (3), 130-138.

Adams, T. B., Bezner, J.R., Garner, L. \& Woodruff, S. (1998). Construct validation of the perceived wellness survey. American Journal of Health Studies, 14 (4). 212-219.

Adler, A. (1973). The problem of homosexuality. Frankfurt am Main: Fischer. (Original work published 1917)

Adler, A. (1973). Social interest: a challenge to mankind. $3^{\text {rd }}$ ed. London: Faber \& Faber Ltd. (Original work published 1933).

Adler, A. (1954). Understanding human nature. $5^{\text {th }}$ ed. (W.B. Wolf, Trans.). New York: Fawcett Premier. (Original work published 1927).

Antonovsky, A. (1987). Unravelling the mystery of health: how people manage stress and stay well. San Francisco, CA.: Jossey-Bass.

Antonovsky, A. (1993). The structure and properties of the sense of coherence scale. Social Science and Medicine, 36 (6), 725-733.

Arbuckle, J.L. (1999). Amos 4.0. Chicago, IL:Smallwaters.

Bethlehem, J. (1999). Cross-sectional research. In H.J. Adér \& G.J. Mellenbergh. (Eds.), Research Methodology in the Social, Behavioural and Life Sciences, 110-142. London: Sage.

Browne, M.W. and Cudeck, R. (1993). Single sample crossvalidation indices for covariance structures. Multivariate Behaviour Research, 24, 445-455.

Byrne, B.M. (2001). Structural equation modelling with AMOS: Basic concepts, applications and programming. Mahwah, NJ: Erlbaum.

Cameron, K.S., Dutton, J.E. \& Quinn, R.E. (2003). Positive organisational scholarship: foundations of a new discipline. San Francisco: Berrett-Koehler Publishers, Inc.

Clark, L.A., \& Watson, D. (1995). Constructing validity: basic issues in objective scale development. Psychological Assessment, 7 (3), 309-319.

Crose, R., Nicholas, D.R., Gobble, D.C. \& Frank, B. (1992). Gender and wellness: a multidimensional systems model for counselling. Journal of Counselling and Development. November/December, 71.

Dunn, H.L. (1961). High level wellness. Washington, DC: Mt Vernon.

Dunn, H.L. (1977). What high level wellness means. Health Values: Achieving High Level Wellness, 1, 9-16.

Ferguson, G.A. \& Takane, Y. (1989). Statistical analysis in psychology and education. New York: McGraw-Hill.

Gemson, D.H., \& Eng, B. (2004). The impact of allergic rhinitis on employee health and productivity. The Business and Health Institute. August.

Harris, R.J. (1975). A primer of multivariate statistics. Academic Press. New York.

Harter, J.K., Schmidt, F.L. \& Keyes, C.L.M. (2003). Well-being in the workplace and its relationship to business outcomes: a review of the Gallup studies. Flourishing positive psychology and the life well-lived. Washington. American Psychological Association, 36, 29-33.

Hettler, B. (1984). Presenting the wellness concept to the uninitiated. In J.P. Opatz. Wellness promotion strategies. 28-38.

Huysamen, G.K. (1994). Methodology for the social and behavioural sciences. Halfway House: Southern Book Publishers.

Huiskamp, A.A. (2004). A framework for an empowerment approach to workplace health promotion of wellness. Paper presented at $2^{\text {nd }}$ South African Work Wellness Conference. Potchefstroom. South Africa, 26 May 2004.

Jöreskog, K.G. \& Sorbom, D. (1993). Testing structural equation models. In K.A. Bolllen \& J.S. Long (Eds) Testing structural equation models. 294-316. Newbury Park, CA: Sage.

Jung, C.G. (1960). The structure and dynamics of the psyche. Collected works: Vol. 8. London: Routledge \& Kegan Paul.

Jung, C.G. (1958). The undiscovered self. New York: Mentor Books.

Keyes, C.L.M. \& Haidt, J. (2003). Flourishing positive psychology and the live well lived. Washington: American Psychological Association. 
Maslow, A.H. (1970). Motivation and Personality. (2nd ed.). New York: Harper \& Row.

Myers, J.E. \& Sweeney, T.J. (2005). Counselling for wellness: theory, research and practice. American Counselling Association.

Myers, J.E. \& Sweeney, T.J. (2003). The indivisible self: an evidence-based model of wellness. Manuscript submitted for publication.

Myers, J.E., Sweeney, T.J. \& Witmer, J.M. (2001). Optimisation of human behavior: promotion of wellness. The Handbook of Counselling. Thousand Oaks, CA: Sage Publications. 641-652.

Mullins, J.L. (1999). Management and organisational behaviour. $5^{\text {th }}$ ed. Financial Times. Pitman Publishing.

Overall, J.E. \& Klett, C.J. (1972). Applied multivariate analysis. New York: McGraw-Hill.

Redelinghuys, F.J. \& Rothmann, S. (2004). Koherensiesin, coping, uitbranding en begeestering in die bediening. Paper presented at the 2nd South African Work Wellness Conference, Potchefstroom, South Africa, 25 March 2004.

Saleebey, D. (1997). The strengths perspective in social work practice. $2^{\text {nd }}$ ed. New York: Longman.

SAS Institute. (2000). SAS users guide: Basics (Release 8.01). Cary, NC.: SAS Institute Inc.

Seligman, M.E.P. \& Csikszentmihalyi, M. (2000). Positive Psychology: an introduction. American Psychologist. January, 55 (1), 5-14

Snyder, C.R., Irving, 1.M. \& Anderson, J.R. (1991). Hope and health. In C.R. Snyder \& D.R. Forsyth (Eds.), Handbook of social and clinical psychology: The health perspective. p. 285305. New York: Pergamon.

Snyder, C.R. \& Lopez, S.J. (2002). Handbook of positive psychology. New York: Oxford University Press.
Steyn, A.G.W., Smit, C.F., Du Toit, S.H.C. \& Strasheim, C. (1995). Moderne statistiek vir die praktyk. $5^{\text {de }}$ uitgawe. Pretoria: JL van Schaik.

Strümpfer, D.J.W. (2002). Psychofortology: review of a new paradigm marching on. Retrieved from http:/www.general. rau.ac/psych.

Strümpfer, D.J.W. (1995). The origins of health and strength: from salutogenesis to fortigenesis. South African Journal of Psychology, 25 (2), 81-89.

Sweeney, T.J. \& Witmer, J.M. (1991). Beyond social interest: striving toward optimum health and wellness. Individual Psychology, 47, 527-540.

The Business and Health Care Archive. (2004). "I won't be in today - the dilemma of incidental absence". Business and Health Institute. August.

Van der Westhuizen, T. (2004). Monday blues costing $R 150 m$. Cape Aurgus. November. (3).

Wissing, M.P.W., \& Van Eeden, C. (1997). Psychological wellbeing: a fortigenic conceptualisation and empirical clarification. Paper presented at the 3rd Annual Congress of the Psychological Society of South Africa. Durban, South Africa, 10-12 th Sept.

Wissing, M.P.W. (2000). Wellness: Construct clarification and a framework for future research and practice. Paper presented at the First South African National Wellness Conference. Port Elizabeth, South Africa, 2-5 May.

Witmer, J.M. \& Sweeney, T.J. (1992). A holistic model for wellness and prevention over the life span. Journal of Counselling \& Development, November/December, 71, 22-35.

Wyatt, W. (2004). Cutting health care cost by creating a culture of wellness. 